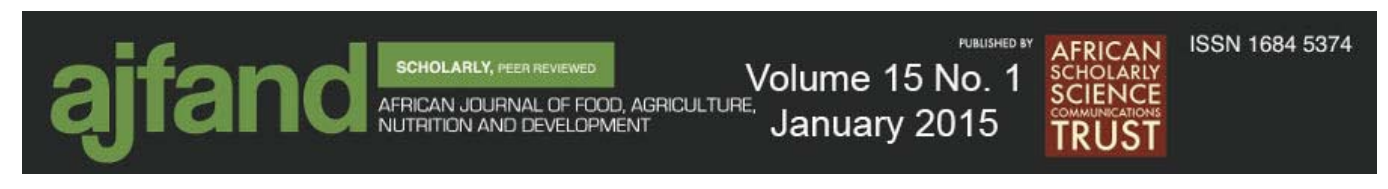

\title{
DIETARY ADEQUACY OF RURAL SCHOOL CHILDREN AMONG BAMBARA GROUNDNUT GROWING FARMERS IN NTCHISI DISTRICT OF MALAWI
}

\author{
Katungwe $\mathbf{P}^{1}$, Mwangwela $\mathrm{A}^{2^{*}}$ and $\mathrm{N}$ Geresomo ${ }^{1}$
}

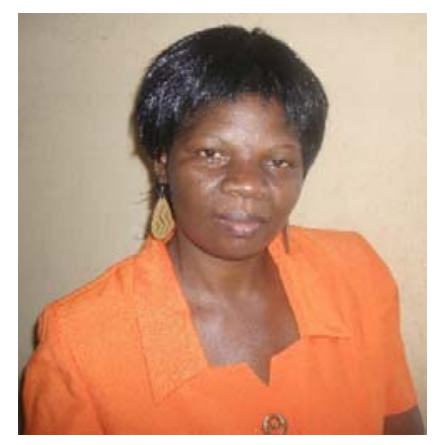

Patricia Katungwe

*Corresponding author email: amwangwela@bunda.luanar.mw

${ }^{1}$ Department of Human Nutrition and Health, Lilongwe University of Agriculture and Natural Resources, P.O. Box 219, Lilongwe, Malawi

${ }^{2}$ Department of Food Science and Technology, Lilongwe University of Agriculture and Natural Resources, P.O. Box 219, Lilongwe, Malawi 


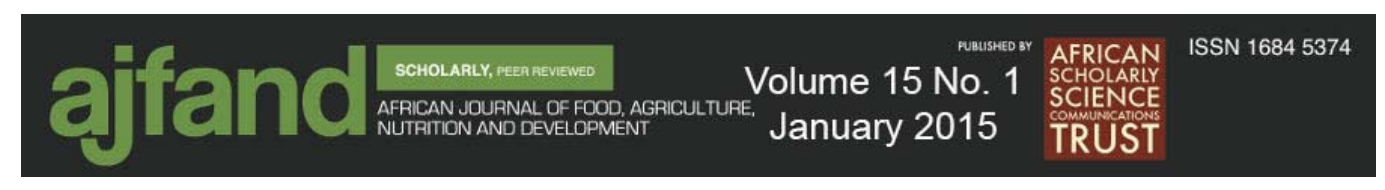

\section{ABSTRACT}

In Malawi, malnutrition among school-aged children as indicated by $30 \%$ stunting, $18 \%$ underweight and 3\% wasting levels is a problem that is being addressed through school feeding programs. The nutritional status of school going children is dependent on household food security, education level of the parents, food preference of the parents and food preparation constraints. These factors affect food consumption patterns of children which is one of the determining factors of nutritional status. A study was, therefore, conducted to explore the food consumption patterns and diet adequacy for school going children aged 7-9 years in Kalira EPA of Ntchisi district in Malawi. Seventy eight school children whose parents were involved in bambara groundnut (Vigna unguiculata) farming were recruited for the study. Demographic information and data on food consumption pattern and intake during postharvest and pre-planting periods was collected using a structured questionnaire. The questionnaire included an interactive 24-hour dietary recall and dietary diversity score (DDS) tools. The children came from mainly male-headed households (91\%) with $6 \pm 2$ members. The household heads had attained upper primary education and their main $(89.7 \%)$ occupation was farming. The school-age children were consuming two carbohydrate based meals per day accompanied with leafy vegetables $(34.1 \%)$ or stewed pulses (46.6\%). Nsima (a stiff porridge made from maize flour) and thin maize flour porridge were the dominant carbohydrate sources in the diet. Only $12 \%$ of the children reported consuming animal source foods. Most of the school children were eating three times or less in a day with lunch and supper as the major meals. The diet of the school children did not meet the recommended dietary allowance for energy $(69 \%)$, fat $(21 \%)$, vitamin A (24\%), iron (65\%) and calcium (28\%). However, the diet was providing adequate protein intake for the children. Snacks in the form of roasted sweet potatoes or maize and bananas were provided to $26.1 \%$ of the school children when going to school, while only $28.4 \%$ were provided with breakfast before going to school. Breakfast consisted of black tea or porridge made from whole maize flour. Diets of the majority $(68 \%)$ of the school going had minimum diversity according to the diversity score. The dietary pattern for the school children was the same during the postharvest and pre-planting period.

Key words: adequacy, diet, diversity, school, children 


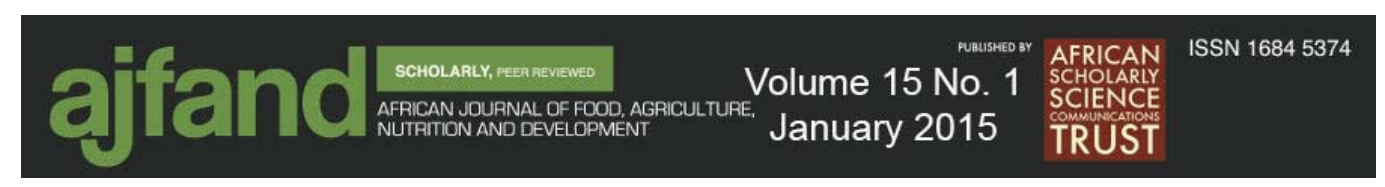

\section{INTRODUCTION}

Prevalence of malnutrition in Malawi among school-aged children is 30\% for stunting, $18 \%$ underweight and 3\% wasting [1]. Malnutrition is one of the contributing factors to reduced mental and physical development of children, hence delayed enrolment, poor physical performance, increased school absenteeism, increased dropouts, and low academic and professional achievements [1]. Nutritional status is a strong determinant of health and neurocognitive performance of school-age children [2]. The school-age period is nutritionally significant because it is the prime time to build up body stores of nutrients in preparation for rapid growth during adolescence [3]. In addition, school children in developing countries perform chores or walk long distances to school, creating a need for energy that is much greater than that of younger children [4]. Good nutrition is essential to minimize illnesses and enhance cognitive development of school children; hence it is imperative that these children meet their energy and nutrient RDAs $[5,6]$. The diet of school-age children in Malawi is mainly composed of starchy staples and vegetables and is inadequate to meet the nutrient requirements of the children [1]. This inadequate diet has been associated with household food insecurity, low education level, parents' food preference and familiarity [7, 8].

In addition, school children usually skip breakfast because of limited time as they seem to be rushing for school or the family just might lack food and time [1,9]. According to a study conducted in the USA, primary school children who skipped breakfast did not make up the differences in dietary intakes at other meals and also did not meet two thirds of the RDA for vitamins and minerals [10]. The findings of a study involving rural Ugandan primary school children indicate that children who ate breakfast had higher scholastic achievement when compared to their counterparts [11].

Although the malnutrition statistics for school-age children in Malawi are less than optimum, there is scanty information on the dietary pattern of school going children especially in rural Malawi. This study was conducted to assess the adequacy of the diet consumed by school going children in Ntchisi district of central Malawi. 


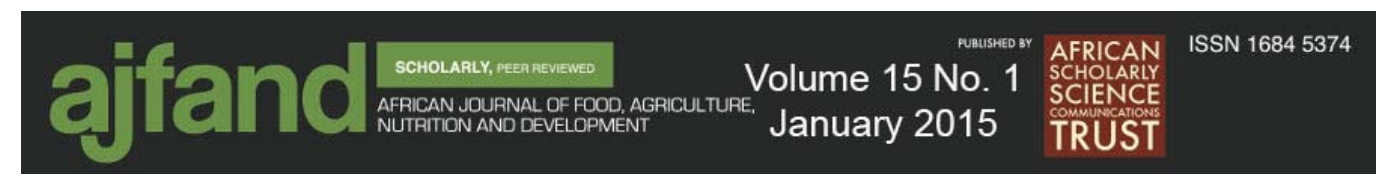

\section{MATERIALS AND METHODS}

\section{Study subjects}

Seventy eight school going children aged 7-9 years from Kalira Extension Planning Area (EPA) participated in the study. The subjects came from three primary schools: Kalira, Ndendere and Kayuwi. This district does not benefit from the national School Feeding Programme and had bambara groundnut promotion activities that were taking place in the area. School going children from households that produced bambara groundnut in 2010/2011 growing period were targeted for this study since the guardians were trained in making snacks from bambara groundnut and the children were involved in sensory evaluation of the snacks. Informed consent from guardians of participating children was sought prior to the study period.

\section{Assessment of dietary nutritional adequacy}

Data on dietary energy and nutrient intake was obtained through interactive 24 hour dietary recall [12]. The study was conducted during post-harvest (August, 2011) and pre-planting (November, 2011) periods. School children were provided with food picture charts depicting the foods commonly consumed in the study area during the season of the survey, two days prior to the household interviews. These foods were identified through market visits, observations and personal interviews of some people in the study area. The children were requested to tick on the food picture chart whatever food they would eat the following day. After two days, the interviewer collected the picture chart from the child and asked the child together with parents/guardians for the amount consumed of the ticked food. The interviewer showed the interviewees calibrated utensils for them to indicate the equivalent amount of consumed food. In this case, the picture chart and calibrated utensils were used as a comparison with the recall to reduce degree of memory lapses [12].

\section{Meal frequency and types of food consumed}

Data on meal frequency and meal pattern was collected by using a semi- structured household questionnaire. Mothers were asked to indicate the type of foods usually consumed by school children at breakfast, lunch, supper and as snacks.

\section{Data analysis}

Dietary data was subjected to Nutri Survey ${ }^{\mathrm{TM}}$ for Windows (2007) to determine dietary energy and nutrient intake and analyzed using SPSS version 16 where descriptive statistics such as means, frequencies and percentages were generated. Student's t- test was used to compare dietary energy and nutrient intakes with the recommended dietary intakes for the children. Data collected through market visits, observations and personal interviews with key informants was processed to determine emerging patterns and common content.

\section{RESULTS}

\section{Demographic description of the households}

The participating children in this study came mainly from male- headed households (91\%). The age of the male household heads ranged from 25 to 87 years while the age 


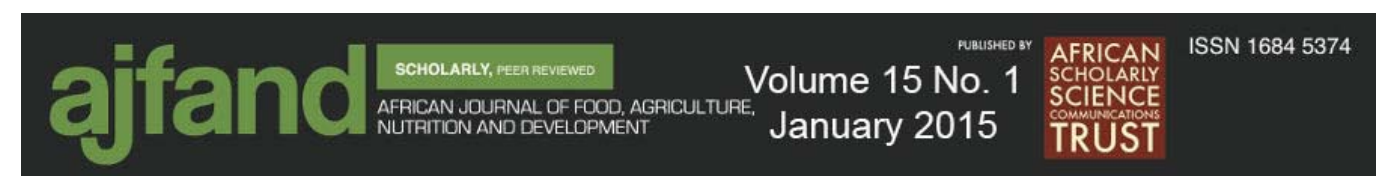

of the female household heads ranged from 14 to 51 years. The households had $6 \pm 2$ members and the adult male members of the households had $6.7 \pm 2.9$ of primary schooling as compared to $2.8 \pm 2.6$ years for the female adults. None of the household members had attended secondary school education. The main occupation of household heads was farming (89.7\%), while $10.3 \%$ were involved in other activities such as trading and making of crafts.

\section{Meal frequency and composition}

The majority $(88.5 \%)$ of the school children were having three or less meals per day (Table 1$)$. Less than half $(28.4 \%)$ of the households provided their school-going children with breakfast consisting of plain whole maize flour (mgaiwa) porridge with sugar, tea without milk and sweet potatoes (Table 2).

All the study children consumed lunch and supper comprising maize stiff porridge (nsima), stewed dry pulses and / or vegetables. Animal source foods such as dry fish, eggs, goat meat, and chicken were consumed by fewer (16\%) children (Table 3 ). Only $26 \%$ of the children were consuming snacks in-between meals such as bananas, sugarcane, roasted maize, roasted soy bean, roasted groundnuts, sweet potatoes and local corn bread (chigumu) made from whole maize flour, sugar, salt and baking soda. These snacks were either consumed at school or at home after school.

\section{Meal composition and dietary diversity scores}

Nsima accompanied with vegetables or stewed pulses such as beans were the main food items consumed by households. Cassava, Irish potatoes, sweet potatoes, groundnuts, cowpeas and bambara groundnut were not consumed during pre-planting period whereas mangoes were consumed during the same period only (Table 4). According to the dietary diversity score, the diets of $70 \%$ of the study children were categorized as having minimum or no diversity (Table 5).

\section{Energy and nutrient dietary adequacy}

The children did not meet their RDAs for energy (69\%), fat (21\%), vitamin A (24\%), iron $(65 \%)$ and calcium $(28 \%)$ during the pre-planting period. Similar trends were observed during the post- harvest period (Table 6).

\section{DISCUSSION}

The average 2.5 meals/day consumed by $88.5 \%$ of the school children is inadequate to meet the nutrient requirements for school-aged children. The general national meal frequency recommendation for school-aged children in Malawi is a minimum of four meals a day comprised of three main meals and nutritious snacks in between the meals [13]. Similar meal frequencies have been reported in rural Uganda where school-age children consumed two to three meals a day consisting of breakfast, lunch and supper [14]. Rural primary school children in Ghana who ate four or more meals a day had higher nutrient intakes than those who ate three or less meals a day [15]. In Nigeria, the prevalence of malnutrition was high among rural primary school children where majority consumed three meals a day [16]. The school children in this study consumed lunch and supper while skipping breakfast. Breakfast was skipped for a number of 


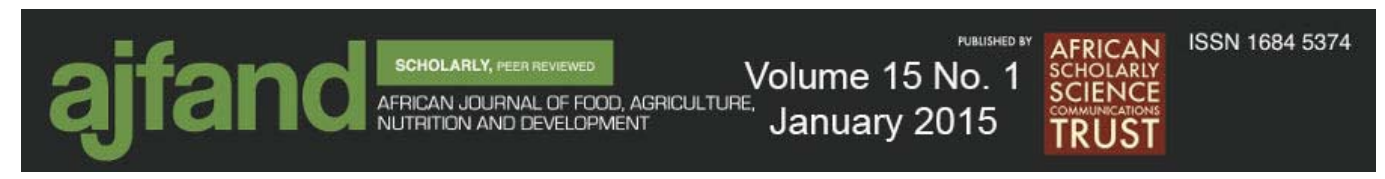

reasons which included lack of food items in the household. Even though whole maize flour porridge was the main breakfast food, the guardians were unlikely to prepare the porridge if the household did not have sugar because family members would consume less or sometimes refuse to eat the food without added sugar. Women do not want to waste their time and flour preparing food that would not be consumed [17]. In addition, there was lack of knowledge among guardians on the importance of breakfast for school children since guardians considered the time $(11: 30 \mathrm{am})$ the children come out of school as early enough to eat the first meal after school. Studies have demonstrated that provision of a daily breakfast improves scholastic achievements among schoolage children [11]. Time constraints for the guardians and the children also contribute to skipping of breakfast $[11,17]$. While the women have to balance the early morning chores such as attending to the farm and fetching water, the children are rushing to arrive at school before 7:30 am, such that preparation and consumption of breakfast is not a priority.

Only $26.1 \%$ of the school aged children consumed snacks in the course of the day. These snacks were either carried from home and consumed at school $(14.8 \%)$ or consumed at home after school. In addition, some children $(15.9 \%)$ were given money to buy snacks such as sweets, freezes (frozen sweetened and colored water), mandasi (wheat flour fritters), zitumbuwa (whole maize flour fritters) and traditional corn bread (chigumu) at school. Chigumu was a favored snack bought and consumed by the children maybe because it was bigger in size for its price. For instance, a piece of 15 $\mathrm{g}$ mandasi was selling at MK10, $6 \mathrm{~g}$ of sweet at MK2.50, freezes at MK5, maize flour fritters $(70 \mathrm{~g})$ at MK10 and a piece of $150 \mathrm{~g}$ of chigumu at MK10. In Tanzania, most primary school children bought snacks (fried potatoes and cassava) that had a bigger portion size, tended to fill their stomachs quickly and were relatively cheaper than the other items [18]. Snacking provides a relief to hunger in- between main meals and increases meal frequency which in turn assists the children to meet their nutrient RDAs. Midmorning snacks are important because they help to improve classroom performance all the way to lunch time [19]. Similarly, studies have shown that a more evenly distributed energy intake throughout the morning by consuming a mid-morning snack improved memory performance in school children with a low socio-economic status [20].

\section{Meal composition and dietary diversity during the postarvest and pre-planting time}

Starchy staples are the dominant foods for all the meals consumed by the children (Table 4) and similar trends have been reported in Uganda [14]. During post-harvest and pre-planting periods in this study, school children consumed similar animal source protein foods, fats and oils, and vegetable foods. However, there was minimal difference in types of legumes, staples and fruits consumed during post-harvest and pre-planting time. Although it was expected that households would have a wider variety of food supply during the post-harvest time since in Malawi, rural households consume their own produce and can buy from the local market at this time. This pattern was exhibited by the availability of bambara groundnuts, cowpeas and groundnuts during the post-harvest period and were out of stock three months later. Consequently, the children consumed more protein and fat in the post-harvest than in pre-planting 


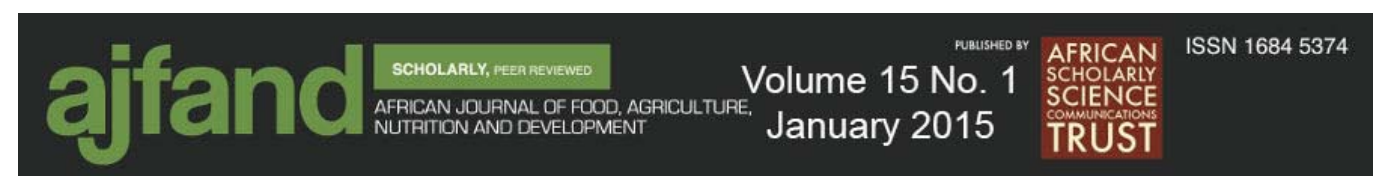

period. The difference in intake can be attributed to periodical variations in food availability in the home and at the market at different times of the year.

The starchy staples were consumed with accompaniments such as leafy vegetables or pulses or animal source foods contributing to the low dietary diversity scores observed in this study. However, only $10 \%$ of the households were combining vegetables and animal food products or pulses. Households consider combining two accompaniments with a starchy staple as wastage. There was inadequate consumption of foods such as pulses, meat and fish that are rich in protein necessary to support rapid growth and development of the children. Additionally, intake of animal source foods is crucial to reduce the negative effect of antinutritional factors (phytic acid and trypsin inhibitors) found in plant food sources which inhibit absorption of nutrients such as iron and zinc [16 ]. Foods from animal sources are rarely consumed in rural areas of Malawi due to cost $[1,21]$. A Malawi National School Health and Nutrition survey in 2006 found that $40 \%$ of school-age children reported to have consumed foods from animal sources on the day before the survey [1]. Inadequate consumption of animal source foods has also been reported in Uganda where children were having staples, legumes and vegetables for lunch while meat and fish were included occasionally [12]. The results of this study indicate that accompaniments were prepared once a day such that foods consumed in a particular day for lunch and supper were similar.

Snacks consumed by the school children $(26.1 \%)$ in the course of the day included: bananas, sugarcane, roasted maize, roasted soy bean, roasted groundnuts, sweet potatoes and chigumu. With the exception of chigumu, the snacks are simple one ingredient carbohydrate- rich foods that guardians can easily prepare in advance for their children.

Diets of most school-going children in Kalira EPA were not adequately diversified; similar results were observed in South Africa, Ghana, Uganda and India [16, 22, 23, 24]. Since dietary diversity score (DDS) is a measure of dietary quality, the diets could not supply all the nutrients at the required level. Studies have shown that high dietary diversity is positively correlated to micro-nutrient adequacy and not energy and macronutrient adequacy [22]. However, in this study, the diet for the school children provided 69 to $73 \%$ of the RDA for energy but providing $150 \%$ of the RDA for protein. In cases of inadequate energy intake, the body uses fats and protein as a source of energy, thus, compromising the unique role of protein for growth and repairing/replacing of body tissues [19]. Inadequate energy intake among these children is of concern because these school children are in the period of rapid growth and development. In addition, the extra demands to carry out chores such as walking long distances of about 2 kilometres to school create a need for energy that is much greater than that of younger children [5]. In a study conducted in 10 developing countries including Malawi, results indicated that DDS is also a measure of household food security status [25]. This implied that, the households of the school children in Kalira EPA were not food secure at the time of this study.

The results on percentage consuming breakfast for school children in Kalira EPA were similar to the $30 \%$ reported for school children in Malawi [1]. Breakfast is important 


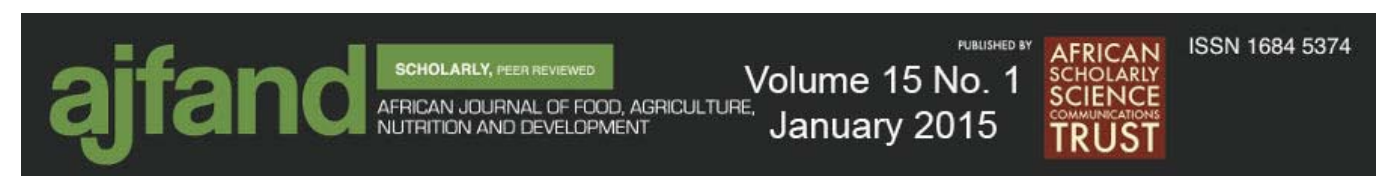

to overall dietary quality, adequacy, academic performance and it helps the children to concentrate in class. Provision of a daily breakfast has been reported to make a significant contribution to a child's mean daily nutrient intake and children who skipped breakfast reported lower intakes of energy, vitamins and minerals $[10,11,16]$. Inadequate dietary intake of vitamin A, iron and calcium among the school children in Kalira EPA could be partly attributed to lack of breakfast. In this case, classroom performance of $71.6 \%$ children in Kalira EPA could be affected after spending the whole night and half of the day without eating any food.

Inadequate intake of fat among the children in Kalira EPA contributed to low energy intake levels. The low dietary fat intake found in this study would contribute to micronutrient deficiencies by compromising absorption of fat soluble vitamins such as Vitamins A, D, E and K [26]. The low dietary fat intake could be due to lack of accessibility of cooking vegetable oil as it is unaffordable by most rural households. Most households have limited purchasing power as $52.4 \%$ of the population lives below the poverty line [27].

Diets of the school children did not meet the RDA for vitamin A. This could be due to inadequate intake of foods rich in this vitamin such as fortified sugar, meat, eggs, carrots, pawpaws, and mangoes, as these contain higher vitamin A and pro-vitamin A carotenoids than green and white leafy vegetables [28]. However, mangoes were consumed during pre-planting period because they were in season. In school, Vitamin A deficiency may lead to increased absenteeism due to illness and thus poor performance in class [1].

The school children could not meet their recommended dietary iron intake because they did not consume animal source foods which are rich in haeme-iron. Likewise, diets of Ghanaian school children provided inadequate amounts of iron, mainly due to inadequate intake of iron rich foods such as meat [25]. To the contrary, Ugandan children met the RDA for iron due to diet comprised of leafy vegetables with iron content of $32-340 \mathrm{mg} / \mathrm{kg}$ [16]. Inadequate dietary iron intake may lead to iron deficiency which results in energy deficit and impairment of learning ability. Additionally, a significant $(p<0.05)$ decline in cognitive function among a control group of 6-11 year-olds has been reported [10]. The children in Kalira EPA were, therefore, at risk of iron deficiency anaemia and its effects.

The main dietary source of calcium in Malawi is fish eaten with bones and green leafy vegetables $[19,12]$. At the same time, per capita consumption of milk in Malawi is very low (4-6 kg/person/year). However, the children in this study were not consuming these foods and as such they could not meet the RDA for calcium. Similarly, the mean intake of calcium was less than half in $95 \%$ of South African primary school children [24]. About $45 \%$ of school children in Kalira EPA consumed green leafy vegetables ( $76 \mathrm{~g}$ in a day), providing about $250 \mathrm{mg}$ of calcium, which was lower than the RDA. Childhood and adolescence are critical times for optimizing peak bone mass deposits and the consequences of inadequate intake of calcium during these periods are poor bone health and osteoporosis [30]. The situation in Kalira EPA required improvement to prevent the named health problems among the children since malnutrition at all 


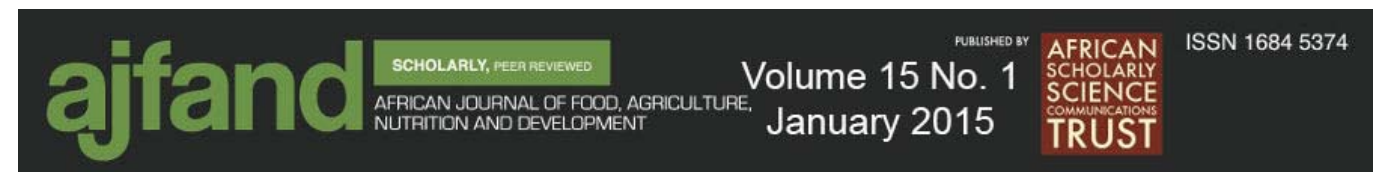

levels can lead to low professional achievements, hence affects the development of the nation due to lack of competent future productive people.

\section{CONCLUSION}

School children in Kalira EPA consumed fewer calories, fats, vitamin A, iron, calcium and more of protein and vitamin $\mathrm{C}$ as compared to their RDA. As such, provision of nutrition education intervention on the importance of consuming breakfast, eating food rich in Vitamin A, iron and calcium among school going children would be essential. In addition, introduction of a school feeding programme in the area would greatly improve the children's nutrient intake. 


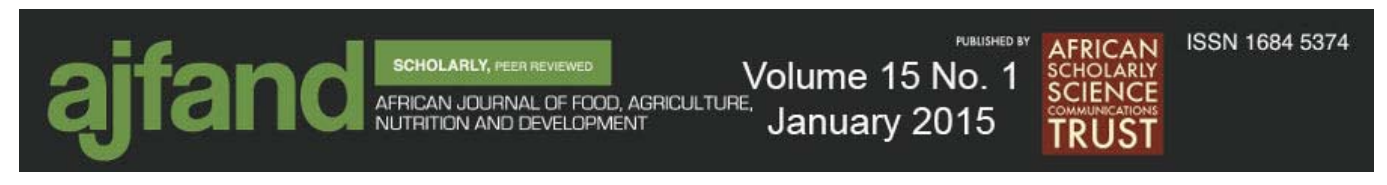

Table 1: Meal frequency of school children in Kalira EPA $(n=78)$

\begin{tabular}{lcc}
\hline $\begin{array}{l}\text { Number of meals consumed } \\
\text { per day }\end{array}$ & Number of children & Percent of children \\
\hline Two meals & 35 & 44.9 \\
Three meals & 34 & 43.6 \\
Four meals & 8 & 10.2 \\
Five meals & 1 & 1.3 \\
\hline
\end{tabular}

Table 2: Types of food eaten at breakfast by school children $(n=25)$ as reported during an interactive $24 \mathrm{hr}$ dietary recall

\begin{tabular}{lcc}
\hline Food & Number of respondents & $\mathbf{\%}$ \\
\hline Black tea with sugar & 6 & 24 \\
Black tea with sugar and buns & 3 & 12 \\
Whole maize flour porridge with sugar & 8 & 32 \\
Black tea with sugar and sweet potato & 2 & 8 \\
Sweet potatoes only & 3 & 12 \\
Chigumu & 3 & 12 \\
\hline Total & $\mathbf{2 5}$ & $\mathbf{1 0 0}$ \\
\hline
\end{tabular}

Table 3: Composition of meals consumed for lunch and supper by school aged children in Ntchisi district $(\mathbf{n}=\mathbf{8 8})$

\begin{tabular}{lrrrr}
\hline Meal composition & \multicolumn{2}{c}{ Lunch } & \multicolumn{2}{c}{ Supper } \\
\cline { 2 - 5 } & n & \% & n & \% \\
\hline Nsima and legume & 30 & 34.1 & 30 & 34.1 \\
Nsima and legume and leafy vegetables & 6 & 6.8 & 6 & 6.8 \\
Nsima and animal source foods & 7 & 8.0 & 6 & 6.8 \\
Nsima and animal source foods and vegetables & 4 & 4.5 & 8 & 9.1 \\
Nsima and leafy vegetables & 41 & 46.6 & 38 & 43.2 \\
\hline
\end{tabular}




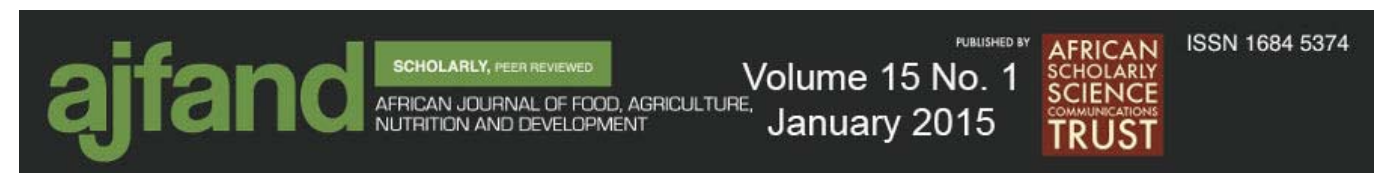

Table 4: Types of food consumed at different periods by school children $(n=78)$

\begin{tabular}{lll}
\hline Food group & Post harvest & Pre-planting \\
\hline Staples & $\begin{array}{l}\text { Nsima, cassava, Irish potatoes, } \\
\text { sweet potatoes, roasted maize. }\end{array}$ & Nsima, roasted maize \\
Animal groups & Eggs, chicken, goat meat. & Eggs, chicken, goat meat \\
Legumes & $\begin{array}{l}\text { Groundnuts, cowpeas, beans, } \\
\text { bambara, roasted soy beans }\end{array}$ & Beans, roasted soy beans \\
Fats and oils & Cooking oil & Cooking oil \\
Vegetables & $\begin{array}{l}\text { Pumpkin leaves, tomatoes, } \\
\text { mustard, onions }\end{array}$ & $\begin{array}{l}\text { Pumpkin leaves, tomatoes, } \\
\text { mustard, onions }\end{array}$ \\
Fruits & Bananas & Bananas, mangoes \\
\hline
\end{tabular}

Table: 5: Dietary diversity scores of school children during post-harvest season $(\mathbf{n}=78)$

\begin{tabular}{cllc}
\hline Diversity scores & Interpretation & $\mathbf{n}$ & $\mathbf{\%}$ \\
\hline $0-2$ & No diversity & 15 & 19.2 \\
3 & Minimum diversity & 38 & 48.7 \\
$4-6$ & High diversity & 25 & 32.1 \\
\hline
\end{tabular}




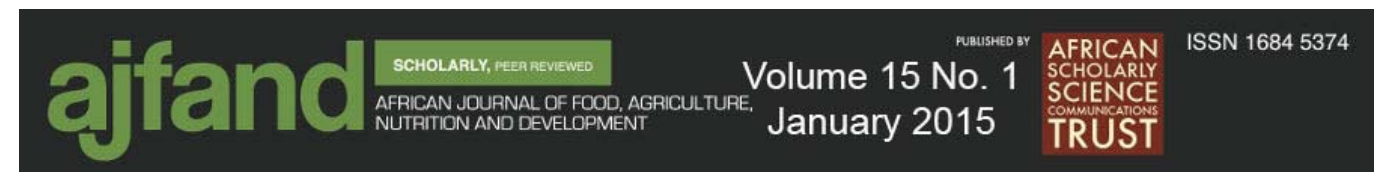

Table 6: Mean values of energy and nutrient dietary intake $(n=78)$

\begin{tabular}{lllcccc}
\hline Nutrient & \multicolumn{5}{c}{ Post harvest period } & \multicolumn{2}{c}{ Pre-planting } & period \\
& RDA & Intake & \% RDA & Intake & \% RDA & p-value $^{\mathbf{1}}$ \\
\hline Energy (kcal) & 1900 & $1389.5 \pm 476.3$ & 73 & $1305.7 \pm 481.8$ & 69 & .295 \\
Protein (g) & 34 & $51.4 \pm 1.6$ & 150 & $40.5 \pm 1.6$ & 118 & .003 \\
Fat (g) & $32-74$ & $22.7 \pm 2.6$ & 43 & $10.7 \pm 2.3$ & 21 & .000 \\
Vitamin A ( $\mu \mathrm{g})$ & 400 & $75.9 \pm 4.0$ & 19 & $95.6 \pm 9.0$ & 24 & .000 \\
Vitamin C mg) & 20 & $49.9 \pm 2.0$ & 250 & $41.3 \pm 3.3$ & 205 & .357 \\
Iron (mg) & 23 & $18.0 \pm 1.7$ & 78 & $14.6 \pm 1.7$ & 65 & .041 \\
Calcium (mg) & 700 & $249.6 \pm 1.9$ & 36 & $198.0 \pm 2.0$ & 28 & .084 \\
\hline${ }^{1}$ Differences were tested with student's t-test & & & &
\end{tabular}




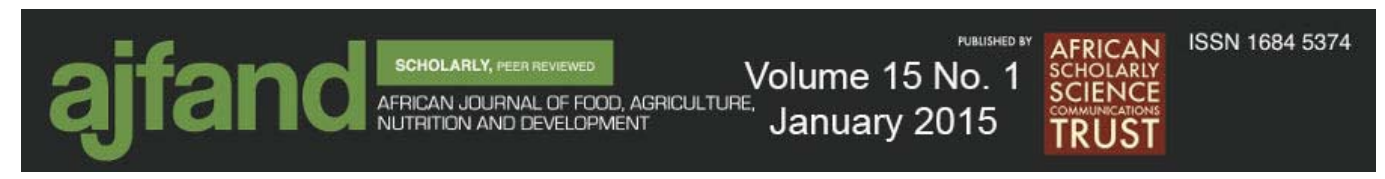

\section{REFERENCES}

1. National Statistical Office (NSO). National School Health and Nutrition Survey report. NSO, Zomba, 2006.

2. United Nations Standing Committee on Nutrition. School-age children: their health and nutrition. SCN News, 2002.

3. Sati V and S Dahiya Nutritional assessment of rural school going children (79 years) of Hisar district, Haryana, 2012. 1:363. doi: 10 4172/scientificreports.363.

4. Del Rosso JM School feeding programmes: Improving effectiveness and increasing the benefit to education. A guide for program managers. The partnership for development 1999. Available from: http://www.schoolandhealth.org (Accessed November, 2012).

5. Kail RV and JC Cavanaugh Human Development: A life span view. Wadsworth, USA. 2010: 243-244.

6. Mann $\mathbf{J}$ and $\mathbf{S}$ Truswell Essentials of Human Nutrition. Oxford University Press, Oxford. 2007: 471-73.

7. Patrick $\mathbf{H}$ and TA Nicklas A review of family and social determinants of children's eating patterns and diet quality. Journal of the American College of Nutrition 2005; 24:83-94.

8. Søndergaard HA and M Edelenbos What parents prefer and children like Investigating choice of vegetable-based food for children. Food Quality and Preference 2007; 18: 949-962.

9. Stuijvenberg ME, Kvalsvig JD, Faber M, Kruger M, Kenoyer DG and AJS Benade Effect of iron, iodine and $\beta$-carotene fortified biscuits on the micronutrient status of primary school children: a randomized controlled study. Am. J. Clin. Nutr. 1999; 69: 497-503.

10. Nicklas TA, Berenson GS, Bao W and LS Weber Breakfast consumption affects adequacy of total daily intake in children. J. Am. Diet. Assoc. 1993; 93: 886-891.

11. Acham H, Kikafunda JK, Malde MK, Oldewage-Theron WH and AA Egal Breakfast, midday meals and academic achievement in rural primary schools in Uganda: implications for education and school health policy. Food and Nutrition Research 2012; 56: 11217.

12. Gibson R Principles of Nutritional Assessment. Oxford University, New York. 2005. 


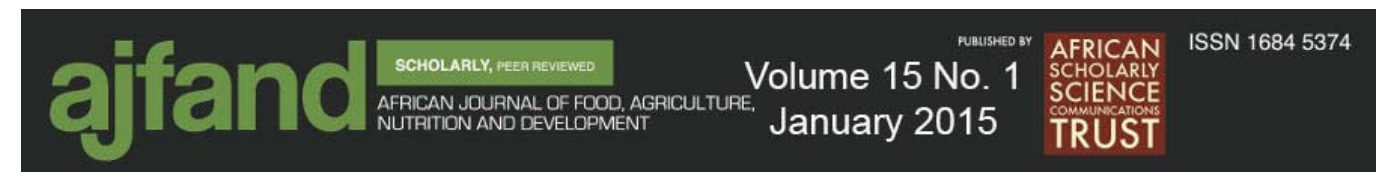

13. Government of Malawi. National Nutrition Policy and Strategic plan. Office of President and Cabinet, Lilongwe. 2007-2012.

14. Tidemann-Andersen I, Acham H, Maage A and M Malde Iron and zinc content of selected foods in the diet of school children in Kumi district, east of Uganda: a cross sectional study. Nutrition Journal 2011; 10:81.

15. Danquah AO, Amoah AN, Steiner-Asiedu $M$ and $C$ Opare-Obisaw Nutritional status of participating and non-participating pupils in the Ghana School Feeding Programme. J. Food Research 2012; 1: 887-895.

16. Olusanya JO Assessment of the food habits and school feeding programme of pupils in rural community in Odogbolu Local Government Area of Ogun State, Nigeria. Pak. J. Nutr. 2010; 9:198-204.

17. Latham MC Human nutrition in the developing world. FAO, Rome. 1997: 134-135.

18. FAO and Sokoine University. Improving the nutritional quality of street foods to better meet the micronutrient needs of school children in urban areas. Rome, Italy. 2007.

19. Rolfes SR, Pinna K and $\mathbf{E}$ Whitney Understanding normal and clinical nutrition. Wadsworth, U.S.A. 2001: 101-130.

20. Muthayya S, Thomas T and K Srinivasan Consumption of a mid-morning snack improves memory but not attention in school children. Physiology and Behaviour. 2007; 90:142-150.

21. Nyambose J, Koski KG and KL Tucker High intra/interindividual variance ratios for energy and nutrient intakes of pregnant women in rural Malawi show that many days are required to estimate usual intake. J. Nutr. 2002; 132: 13131318 .

22. Mirmiran P, Azadbakht L, Esmaillzadeh A and F Aziz Dietary diversity score in adolescents - a good indicator of the nutritional adequacy of diets: Tehran lipid and glucose study. Asia Pacific Journal of Clinical Nutrition. 2004; 13: 56-60.

23. Labadarios D, Steyn NP, Maunder E, Maclntryre U, Gerlicke G, Swart R, Huskisson J, Dannhauser A, Vorster HH, Nesmvuni AE and JH Nel The national food consumption survey (NFCS): South Africa, 1999. Public Health Nutrition. 2005; 8: 533-543.

24. Osei-Boadi K, Lartey A, Marquis GS and EK Colecraft Dietary intakes and iron status of vegetarian and non- vegetarian children in selected communities in Accra and Cape Coast, Ghana. African Journal of Food, Agriculture, Nutrition and Development. 2012; 12: 5822-5842. 


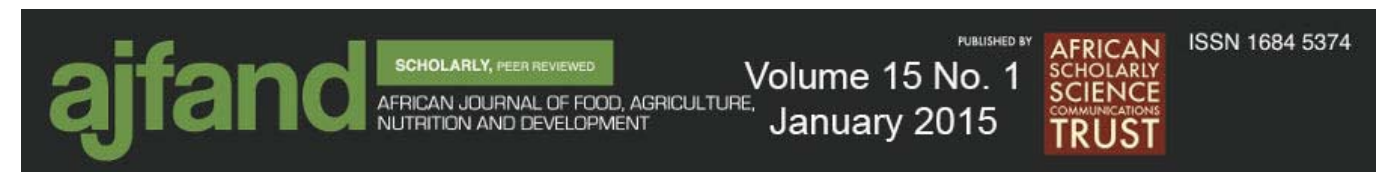

25. Haddinott $\mathbf{J}$ and $\mathbf{Y}$ Yohannes Dietary diversity as a food security indicator. Food Consumption and Nutrition Division Discussion Paper. 2002; 136: 4167.

26. Malawi Government. Malawi Growth and Development Strategy. Ministry of Finance and Development Planning, Lilongwe, 2006.

27. Nestel $\mathbf{P}$ and $\mathbf{R}$ Nalubola B-carotene in fruits is more bioavailable than that in vegetables, 2003. Available from http://ilsi.org. (Accessed February, 2012).

28. Coulston AM The role of dietary fats in plant-based diets. American Journal of Clinical Nutrition. 1999; 70: 125-155.

29. Tebug S F, Chikagwa-Malunga $\mathbf{S}$ and $\mathbf{S}$ Wiedemann On-farm evaluation of dairy farming innovations uptake in northern Malawi, 2012. Available from from http://www.lrrd.org//rrd24/5/tebu24083.htm. (Accessed January, 2014).

30. Schlenker ED and S Long William's essentials of nutrition and diet therapy. Mosby Elsevier, Canada. 2007: 147-153. 